\title{
Risk variables of external apical root resorption during orthodontic treatment
}

Maria Carolina Feio Barroso ${ }^{1}$, Renan Lana Devita², Eugênio José Pereira Lages ${ }^{3}$, Fernando de Oliveira Costa ${ }^{4}$, Alexandre Fortes Drummond ${ }^{5}$, Henrique Pretti ${ }^{6}$, Elizabeth Maria Bastos Lages ${ }^{5}$

Introduction: External apical root resorption (EARR) is an adverse outcome of the orthodontic treatment. So far, no single or associated factor has been identified as responsible for EARR due to tooth movement.

Objective: This study investigated the association of risk variables (age, gender, extraction for orthodontic treatment and Angle classification) with EARR and orthodontic treatment.

Method: The sample ( $n=72)$ was divided into two groups according to presence $(n=32)$ or absence $(n=40)$ of EARR in maxillary central and lateral incisors after orthodontic treatment.

Results: There were no statistically significant differences in EARR according to age, gender, extraction or type of malocclusion $(\mathrm{p}>0.05)$.

Conclusion: The risk variables examined were not associated with EARR in the study population.

Keywords: Orthodontics. Root resorption. Tooth movement.

${ }^{1}$ Graduate Student of Orthodontics, FO-UFMG.

${ }^{2}$ Undergraduate student, FO-UFMG

${ }^{3} \mathrm{PhD}$ Student, Periodontics Department, FO-UFMG.

${ }^{4}$ Associate Professor, Periodontics Department, FO-UFMG.

${ }^{5}$ Associate Professor, Orthodontics Department, FO-UFMG.

${ }^{6}$ Assistant Professor, Orthodontics Department, FO-UFMG.
How to cite this article: Barroso MCF, Devita RL, Lages EJP, Costa FO, Drummond AF, Pretti H, Lages EMB. Risk variables of external apical root resorption during orthodontic treatment. Dental Press J Orthod. 2012 Mar-Apr;17(2):39.el-7.

Submitted: March 11, 2009 - Revised and accepted: August 16, 2009

" The authors report no commercial, proprietary, or financial interest in the products or companies described in this article.

Contact address: Maria Carolina Feio Barroso

Faculdade de Odontologia - UFMG / Dpto. de Ortodontia e Odontopediatria Av. Antônio Carlos, 6627 - Pampulha - Cep: 31.270-901 - Belo Horizonte / MG - Brazil E-mail: carolfeio@yahoo.com.br 


\section{INTRODUCTION}

External apical root resorption (EARR) is a relevant pathological side effect ${ }^{2,10}$ of orthodontic treatment that leads to permanent loss of the dental root apex. According to Brezniak and Wasserstein $^{11}$ and Hartsfield Jr et al, ${ }^{16}$ it is a frequent iatrogenic result of orthodontic treatment, particularly in maxillary incisors.

The prevalence of EARR associated with orthodontic treatment is variable. Histological studies have reported a high prevalence, whereas clinical trials found a varied prevalence depending on the method used. ${ }^{9}$ EARR affects central maxillary incisors primarily; over one third of all subjects that undergo orthodontic treatment are affected by having resorptions greater than $3 \mathrm{~mm}$, whereas severe resorption (greater than $5 \mathrm{~mm}$ ) affects 2 to $5 \%$ of the orthodontic population. ${ }^{16,30}$ According to Capelozza Filho and Silva Filho, ${ }^{12}$ root resorption is found in most (90.5\%) permanent teeth that undergo orthodontic treatment; such areas are shallow and broad (surface resorption) and are always repaired. According to Consolaro, ${ }^{13}$ severe and structurally important root resorption affects $10 \%$ of the subjects that undergo orthodontic treatment.

EARR associated with orthodontic treatment is an important concern. Up to $3 \mathrm{~mm}$ of apical third loss results in limited damage, and root resorptions of such magnitude are assumed as a part of the biological cost of treatment. These side effects or iatrogenic events are practically unavoidable in orthodontic practice and are classified as clinically acceptable. However, they should not be seen as normal, physiological or part of the apical remodeling process. ${ }^{13}$

Apical resorptions that exceed $3 \mathrm{~mm}$ result in loss of tooth support due to a reduction of the supporting periodontium. Levander and Malmgren ${ }^{22}$ analyzed the mobility of teeth with severe EARR (resorption of $1 / 3$ of the root or more) five to fifteen years after the active treatment phase and evaluated mobility associated with root length and supporting alveolar bone. They found a significant correlation between tooth mobility and total and intra-alveolar root length and concluded that there was risk of tooth mobility in maxillary incisors with severe root resorption during orthodontic treatment if the remaining root length was $\leq 9 \mathrm{~mm}$.
Although several studies have investigated root resorption, no single or associated factor has been identified as responsible for EARR due to orthodontic treatment. ${ }^{3}$

The etiology of EARR associated with orthodontic treatment is multifactorial and involves environmental and host factors. Several variables have been described in the literature as possible risk factors for EARR: Tooth anomalies and the shape of root and alveolar bone crest, ${ }^{13,14,20,27}$ type and severity of malocclusion, $, 5,6,14,17,27,30$ amount of tooth movement, ${ }^{5,18,23,26}$ extractions for orthodontic treatment, ${ }^{7,24,28}$ cell and molecular mechanisms of osteoblast regulation, ${ }^{19}$ factors associated with the technique used, such as magnitude of force applied, ${ }^{1,25}$ treatment duration, ${ }^{15,21}$ type of orthodontic treatment, ${ }^{1,6,7,28}$ age and gender, $, 5,6,7,14,17,20,26,27$ individual variations and genetic factors. ${ }^{2,3,14}$

This study investigated the association of age, gender, orthodontic extractions and Angle classification with external apical root resorptions resulting from orthodontic treatment.

\section{MATERIAL AND METHODS Sample}

This study enrolled subjects over 18 years of age that received total fixed orthodontic treatment in the Graduate Program in Orthodontics of the School of Dentistry of Minas Gerais Federal University. The sample was divided into two groups according to presence (case group) or absence (control group) of EARR in maxillary central and lateral incisors.

\section{Inclusion criteria}

Participants were included if good quality periapical radiographs obtained before and after orthodontic treatment were available, and pretreatment radiographs showed no resorption.

\section{Exclusion criteria}

All subjects with crown fractures or restorations in the incisal edge of maxillary incisors were excluded.

\section{Authorization of participants and parents or guardians}

All participants over the age of 18 years and the parents or guardians of underage participants signed an informed term of consent after receiving explanations about the justification for radiographs 


\section{Data collection}

\section{Clinical analysis}

Data about age, gender, extractions for orthodontic treatment and Angle classification of malocclusion were collected directly from patient charts.

\section{Radiographic analysis}

To evaluate the presence or absence of EARR, all periapical radiographs were digitalized using an HP Scanjet scanner 3570c at a resolution of 300 dpm. Images were analyzed directly on the computer screen using the software ARARA - An environment for image segmentation ${ }^{4}$ (Fig 1 ).

Measurements were made according to the method described by Linge and Linge, ${ }^{23}$ modified by Brezniak et al. ${ }^{8}$ To determine and calculate the changes in tooth and root lengths between two radiographs, those authors used, among other landmarks, the midpoint (M) for the cement enamel junction (CEJ), defined as the midpoint between the mesial and the distal CEJ (Fig 2).

After this landmark has been identified, the following distances were measured for all periapical radiographs: from $\mathrm{M}$ to root apex, as a measure of root length, and from $\mathrm{M}$ to incisal edge as a measure of crown length. These measurements are similar to the rl, r2, cl and c2 distances described by Linge and Linge ${ }^{23}$ (Fig 2).

Changes in root length due to treatment were mathematically calculated as follows: during orthodontic treatment, the length of the crown does not change, unless it is fractured or restored. Therefore, the ratio between initial (c1) and final (c2) length of the crown defines the radiographic change factor.
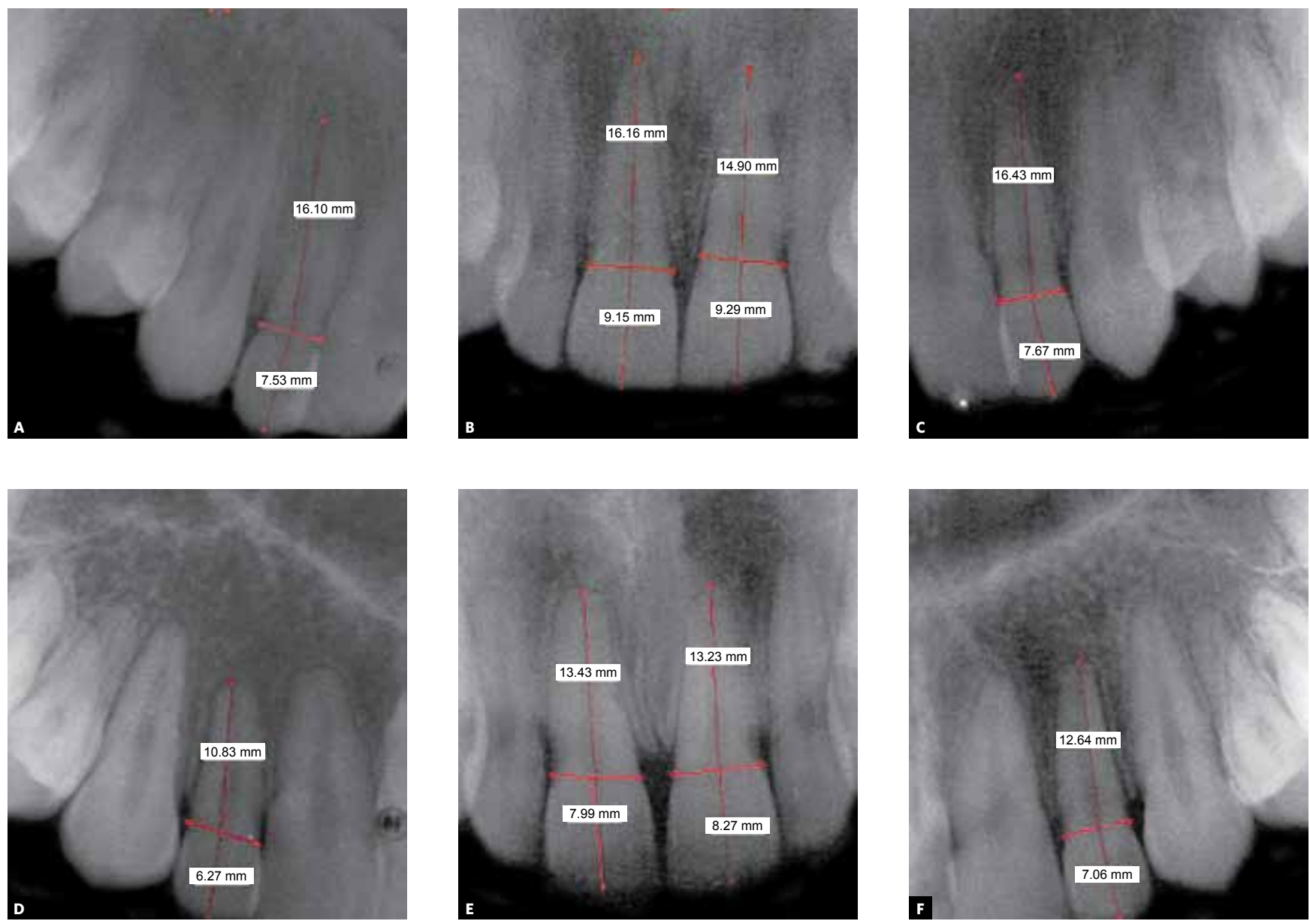

Figure 1 - Digitalized periapical radiographs before $(\mathbf{A}, \mathbf{B}, \mathbf{C})$ and after $(\mathbf{D}, \mathbf{E}, \mathbf{F})$ orthodontic treatment with maxillary incisors measurements of crowns and roots. 


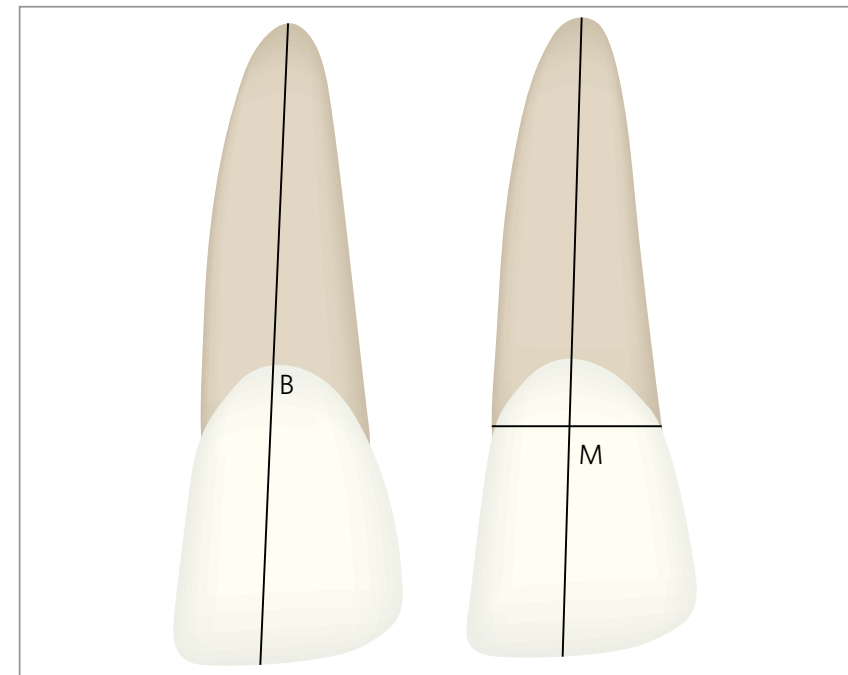

Figure 2 - Identification of midpoint (M) (Brezniak et al $\left.{ }^{8}\right)$.

If there was no change in root length during treatment, the ratio between initial and final root length ( $\mathrm{r} 1 / \mathrm{r} 2)$ should be the same as the ratio between initial and final crown length $(\mathrm{cl} / \mathrm{c} 2)$. If the root length shortens during treatment, the amount of resorption is calculated as rl-r2(cl/c2).

Therefore, subjects with less than $2 \mathrm{~mm}$ EARR were defined as not affected and included in the control group, and those with only one incisor with EARR $\geq 2 \mathrm{~mm}$ were included in the case group (Fig 3 ).

\section{Examiner calibration}

To observe examiner calibration, a single examiner repeated measurements of 20 radiographs at an interval of seven days between readings. Results were recorded as presence or absence of readings below $0.5 \mathrm{~mm}$. Kappa statistics was used to evaluate the reproducibility of radiograph measurements. ${ }^{29}$

\section{Statistical analysis}

Descriptive variables are presented as percentages, mean, and standard deviations (SD)

The Student t test, a chi-square test and the Fischer exact test were used to analyze variables below 5 . The level of significance was set at $5 \%(\mathrm{p}<0.05)$.

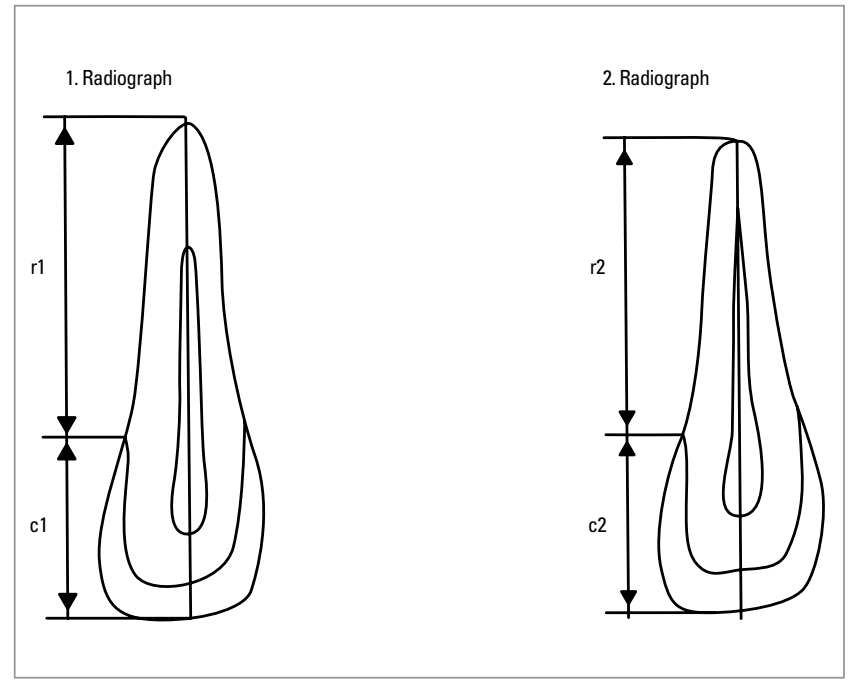

Figure 3 - Correction factor for difference in root length: $f=c 1 / c 2$; external root resorption: $\mathrm{r} 1-\mathrm{r} 2(\mathrm{c} 1 / \mathrm{c} 2)$ (Linge and Linge $\mathrm{e}^{23}$ ).

\section{RESULTS}

The sample included 72 subjects divided into two groups according to presence (case group, $\mathrm{n}=32$ ) or absence (control group, $\mathrm{n}=40$ ) of EARR in maxillary central and lateral incisors after orthodontic treatment.

Sample characteristics (age, gender, orthodontic extractions, Angle classification) and the analysis of associations between variables and EARR occurrence are presented.

\section{Sample characteristics}

Age

Age ranged from 10 to 50 years, and mean age was 15.7 years $( \pm 7.3)$. In the control group, age ranged from 10 to 34 years, and mean age was 14.6 years; in the EARR group, age ranged from 10 to 50 years, and mean age was 17.2 years. There was a significant difference in age between groups (Table 1).

\section{Gender}

Figure 4 shows the classification of subjects according to gender. EARR was present in $42.1 \%$ of the women and $47 \%$ of the men. There were no significant differences in EARR regarding gender $(\mathrm{p}=0.673)$. 


\section{Extractions for orthodontic treatment}

EARR was found in $43.3 \%$ of the subjects in the group that had extractions, and in $45.2 \%$ in the group without extractions. There were no significant differences between groups with or without extractions ( $\mathrm{p}=0.873)$ (Fig 5).

\section{Angle malocclusion classification}

EARR was found in $41.4 \%$ of all Class I subjects, $45.4 \%$ of the Class II subjects, and $55.5 \%$ of Class III malocclusion subjects, but these differences were not statistically significant $(\mathrm{P}=0.750)$ (Fig 6).

\section{DISCUSSION}

It has been widely accepted that EARR is a frequent iatrogenic outcome of the orthodontic treatment, particularly in maxillary incisors. It is assumed that compression of the periodontal ligament, which reduces or interrupts blood supply, leads to aseptic necrosis and during removal of necrotic tissue by macrophages and osteoclasts, the root may be injured. ${ }^{10,16}$ Meanwhile, the etiology of EARR remains unclear and subject to the effect of innumerable risk variables. Although several studies have investigated this topic, no single or associated factor has been identified as responsible for EARR due to orthodontic treatment. ${ }^{3}$

Previous studies focused on the magnitude of the force applied, ${ }^{1,25}$ duration, ${ }^{1521}$ and the type of orthodontic treatment ${ }^{1,6,7}$ have not established a causal relation between these factors and EARR.

Over the wide range of causal variables related to EARR, this study analyzed the effect of age, gender, extractions for orthodontic treatment and type of malocclusion. Our findings did not reveal any statistically significant differences regarding these variables. The results should be interpreted carefully because associations might have been affected by the study sample.

Difficulties in obtaining a standardized and homogeneous sample are often found in similar studies. In addition, final records from patients that have completed orthodontic treatment are not always available. When available, radiographs are not standardized and, thus, considered useless because they do not show the anatomic landmarks necessary for measurements. Therefore, limitations due to sample size are frequent.
Table 1 - EARR according to age.

\begin{tabular}{cccccc} 
Group & Min. & Max. & Mean & s.d. & p \\
\hline Global & 10 & 50 & 15.78 & 7.32 & \\
No EARR & 10 & 34 & 14.60 & 4.13 & 0.162 \\
With EARR & 10 & 50 & 17.25 & 9.85 & \\
\hline
\end{tabular}

Note: Statistical significance according to Student's t test.

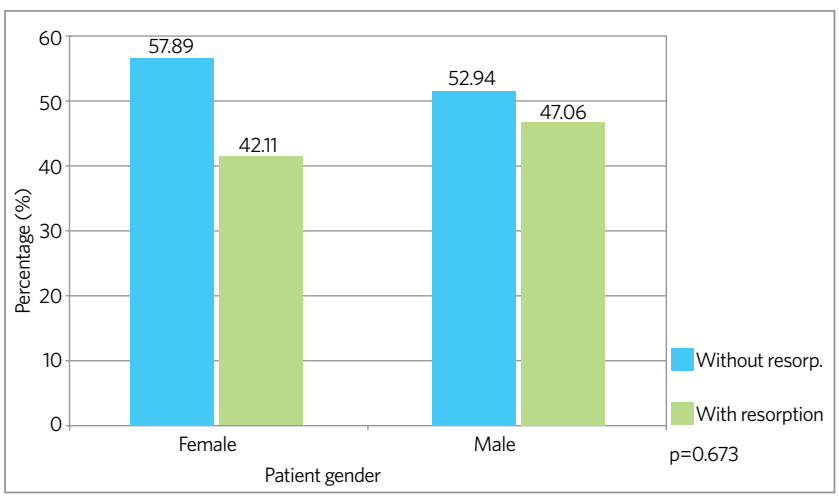

Figure 4 - Classification of subjects according to EARR and gender. Note: Statistically significant difference according to chi-square test.

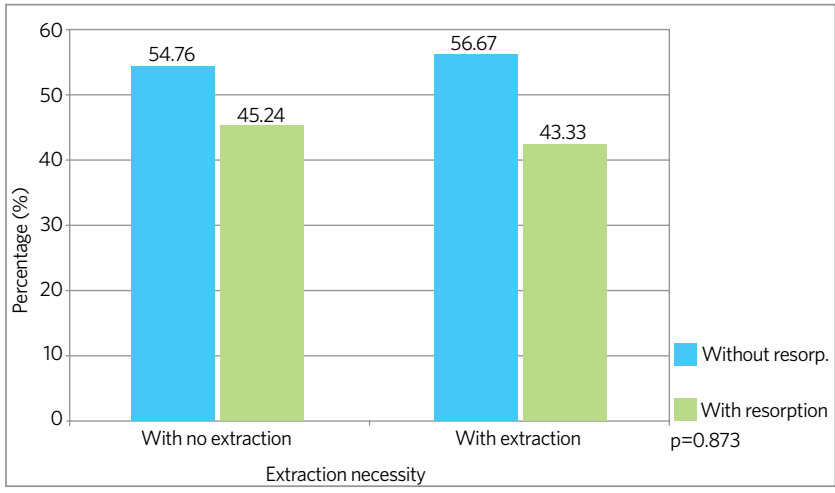

Figure 5 - Classification of subjects according to EARR and extractions. Note: Statistically significant difference according to Fisher exact test.

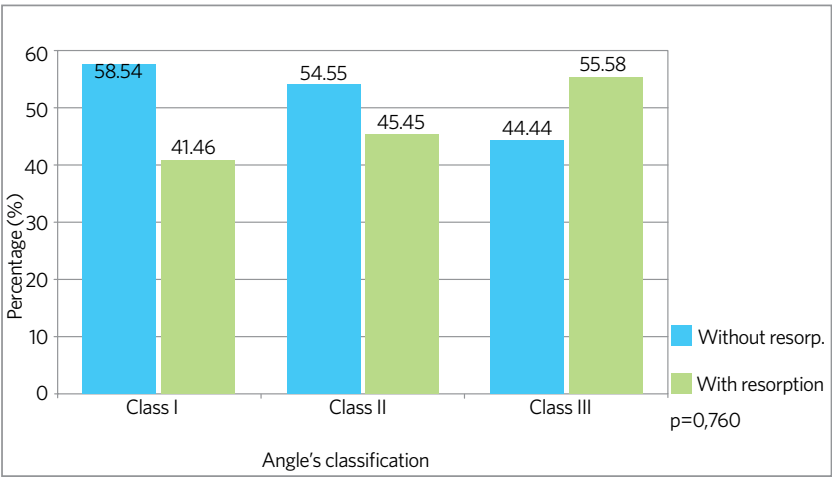

Figure 6 - Classification of subjects according to EARR and Angle malocclusion classification.

Note: Statistically significant difference according to Fisher exact test. 
This study showed that age does not seem to be a significant factor in EARR, a finding similar to those reported by several authors in different studies that investigated the association of this variable with EARR. ${ }^{5,14,17}$

In accordance to our study, several investigations have demonstrated that there is an association between gender and EARR. ${ }^{6,7,26,27}$ According Kjaer $^{20}$ (cited by Hartsfield $\mathrm{Jr}$ et $\mathrm{al}^{16}{ }^{16}$ ) a greater prevalence of EARR among women was found.

Although we did not find an association between type of malocclusion and EARR, several types of malocclusion, both dental and skeletal, have been classified as risk factors for EARR. Several factors are involved in the treatment of each type of malocclusion, which may potentialize risk variables in EARR, and the existing literature about this topic is still controversial. $5,17,27,30$

The severity of malocclusion may be associated with the extent of orthodontic tooth movement, and the duration of orthodontic treatment may be positively associated with the extent of EARR. ${ }^{26}$ According to Baumrind et al, ${ }^{5}$ Horiuchi et al, ${ }^{18}$ and Linge and Linge, ${ }^{23}$ orthodontic tooth movement has been responsible for up to one third of all EARR variation, whereas Parker and Harris ${ }^{26}$ assigned $90 \%$ of all EARR variation to the extent of tooth movement. In addition, in cases of more severe overjet, a greater amount of retraction should be achieved during orthodontic treatment, and, therefore, there is, in fact, a chance of greater incisor root resorption. ${ }^{6,14}$

This study did not find any association between extractions for orthodontic treatment and EARR. Extractions might affect the degree of EARR because they are associated with the amount of tooth movement required to close remaining extraction sites, differently from non-extraction cases., ${ }^{7,24}$ Therefore, greater EARR may be expected in cases of extraction of four premolars than in cases without extractions or with the extraction of only two maxillary premolars.

\section{CONCLUSION}

There were no statistically significant differences in EARR according to age, gender, extraction for orthodontic treatment, or Angle malocclusion classification. 


\section{REFERENCES}

1. Alexander SA. Levels of root resorption associated with continuous arch and sectional archmechanics. Am J Orthod Dentofacial Orthop. 1996;110(3):321-4.

2. Al-Qawasmi RA, Hartsfield JK Jr, Everett ET, Flury L, Liu L, Foroud TM, et al. Genetic predisposition to external apical root resorption. Am J Orthod Dentofacial Orthop. 2003;123(3):242-52.

3. Al-Qawasmi RA, Hartsfield JK Jr, Everett ET, Weaver MR, Foroud TM, Faust DM, et al. Root resorption associated with orthodontic force in inbred mice: genetic contributions. Eur J Orthod. 2006;28(1):13-9. Epub 2005 Dec 22.

4. Andrade MC. An interactive algorithm for image smoothing and segmentation. Eletr Letters Comp Vis Image Analysis. 2004;4(1):32-48.

5. Baumrid S, Korn EL, Boyd RL. Apical root resorption in orthodontically treated adults. Am J Orthod Dentofacial Orthop. 1996;110(3):311-20.

6. Beck BW, Harris EF. Apical root resorption in orthodontically treated subjects: Analysis of edgewise and light wire mechanics. Am J Orthod Dentofacial Orthop. 1994;105(4):350-61.

7. Blake M, Woodside DG, Pharoah MJ. A radiographic comparison of apical root resorption after orthodontic treatment with the edgewise and Speed appliances. Am J Orthod Dentofacial Orthop. 1995;108(1):76-84.

8. Brezniak N, Goren S, Zoizner R, Dinbar A, Arad A, Wasserstein A, et al. A comparison of three methods to accurately measure root length. Angle Orthod. 2004;74(6):786-91.

9. Brezniak N, Wasserstein A. Root resorption after orthodontic treatment. Part 1. Literature review. Am J Orthod Dentofacial Orthop. 1993;103(1):62-6.

10. Brezniak N, Wasserstein A. Orthodontically induced inflammatory root resorption. Part I: The basic science aspects. Angle Orthod. 2002;72(2):175-9.

11. Brezniak N, Wasserstein A. Orthodontically induced inflammatory root resorption Part II: The clinical aspects. Angle Orthod. 2002;72(2):180-4

12. Capelozza Filho L, Silva Filho O. Reabsorção radicular na clínica ortodôntica: atitudes para uma conduta preventiva. Rev Dental Press Ortod Ortop Facial. 1998;3(1):104-26.

13. Consolaro A. Movimentação dentária induzida: biologia aplicada à prática clínica. In: Consolaro A. Reabsorções dentárias nas especialidades clínicas. 2ª ed. Maringá: Dental Press; 2005. p. 304-51.

14. Harris EF, Kineret SE, Tolley EA. A heritable component for external apical root resorption in patients treated orthodontically. Am J Orthop Dentofacial Orthop. 1997;111(3):301-9.

15. Harry MR, Sims MR. Root resorption in bicuspid intrusion. A scanning electron microscope study. Angle Orthod. 1982;52(3):235-58
16. Hartsfield JK Jr, Everett ET, Al-Qawasmi RA. Genetic factors in external apical root resorption and orthodontic treatment. Crit Rev Oral Biol Med. 2004;15(2):115-22.

17. Hendrix I, Carels C, Kuijpers-Jagtman AM, Van 'T Hof M. A radiographic study of posterior apical root resorption in orthodontic patients. Am J Orthod Dentofacial Orthop. 1994;105(4):345-9.

18. Horiuchi A, Hotokezaka H, Kobayashi K. Correlation between cortical plate proximity and apical root resorption. Am J Orthod Dentofacial Orthop. 1998;114(3):311-8

19. Kanzaki H, Chiba M, Shimizu Y, Mitani H. Dual regulation of osteoclast differentiation by periodontal ligament cells through RANKL stimulation and OPG inhibition. J Dent Res. 2001;80(3):887-91.

20. Kjaer I. Morphological characteristics of dentitions developing excessive root resorption during orthodontic treatment. Eur J Orthod. 1995;17(1):25-34.

21. Kurol J, Owman-Moll P, Lugren D. Time-related root resorption after application of a controlled continuous orthodontic force. Am J Orthod Dentofacial Orthop. 1996;110(3):303-10

22. Levander $\mathrm{E}$, Malmgren $\mathrm{O}$. Long-term follow-up of maxillary incisors with severe apical root resorption. Eur J Orthod. 2000;22(1):85-92.

23. Linge $\mathrm{L}$, Linge $\mathrm{BO}$. Patient characteristics and treatment variables associated with apical root resorption during orthodontic treatment. Am J Orthod Dentofacial Orthop. 1991;99(1):35-43.

24. McNab S, Battistutta D, Taverne A. External root resorption following orthodontic treatment. Angle Orthod. 2000;70(3):227-32.

25. Owman-Moll P, Kurol J, Lundgren D. Repair of orthodontically induced root resorption in adolescents. Angle Orthod. 1995;65(6):403-8

26. Parker RJ, Harris EF. Directions of orthodontic tooth movements associated with external apical root resorption of the maxillary central incisor. Am J Orthod Dentofacial Orthop. 1998;114(6):677-83.

27. Sameshima GT, Sinclair PM. Predicting and preventing root resorption: Part I. Diagnostic factors. Am J Orthod Dentofacial Orthop. 2001;119(5):505-10.

28. Sameshima GT, Sinclair PM. Predicting and preventing root resorption: Part II. Treatment factors. Am J Orthod Dentofacial Orthop. 2001;119(5):511-5.

29. Siegel S, Castellan NJ. Nonparametric statistics for the behavioral science. 2a ed. New York: McGraw-Hill Book; 1988.

30. Taithongchai R, Sookkorn K, Killiany DM. Facial and dentoalveolar structure and the prediction of apical root shortening. Am J Orthod Dentofacial Orthop. 1996;110(3):296-302 